\title{
マイクロ波水熱法による籾殼からの活性炭合成
}

\author{
稲田幹, 古賀 貴寛, 田中 優実, 榎本 尚也, 北條 純一 \\ 九州大学大学院工学研究院応用化学部門, $\bar{T} 819-0395$ 福岡市西区元岡 744.
}

\section{Synthesis of Activated Carbon from Rice Chaff by Microwave Hydrothermal Method}

\author{
Miki Inada, Takahiro Koga, Yumi Tanaka, Naoya Enomoto and Junichi Hojo \\ Department of Applied Chemistry, Faculty of Engineering, Kyushu University, 744 Motooka, Nishi-ku, Fukuoka 819-0315, Japan.
}

Received July 4, 2011

\section{SYNOPSIS}

Rice chaff can be converted into activated carbon by alkaline treatment at high temperature. In this study, we tried to synthesize activated carbon from rice chaff by microwave hydrothermal treatment with $\mathrm{NaOH}$ solution. Rice chaff was heated at $700^{\circ} \mathrm{C}$ for $1 \mathrm{~h}$ in $\mathrm{N}_{2}$ after $\mathrm{HCl}$ treatment to remove impurity, such as alkali metals, resulting in the formation of charcoal. The charcoal was mixed with $\mathrm{NaOH}$ aqueous solution, and then heated at $100^{\circ} \mathrm{C}$ under microwave irradiation. After heating, the product was separated by filtration, washed with deionized water and dried at $50^{\circ} \mathrm{C}$. The specific surface area of product was $1060 \mathrm{~m}^{2} / \mathrm{g}$ under microwave irradiation and 690 $\mathrm{m}^{2} / \mathrm{g}$ by conventional heating with autoclave, which indicates that microwave hydrothermal treatment is effective for activation of charcoal.

\section{KEY WORDS}

rice chaff, activated carbon, hydrothermal treatment, microwave irradiation

\section{1 緒 言}

活性炭は, マクロ孔からミクロ孔までの多種多様な細孔が 炭素内部に網目状に張り巡らされた多孔質炭素材料である1). 比表面積が非常に高く, 種々の物質を吸着可能であることか ら, 水質浄化, ガス分離など, 幅広い分野で使用されている. 近年は, キャパシタなどの電極材料への応用も展開されてお り, 高比表面積だけでなく, 吸着質に適した表面制御も重要 となっている.

活性炭は炭素物質を高温でガスや薬品と反応させる賦活処 理によって作られる. 現在用いられている原料には, 木材,の こくず, ヤシ殼, パルプ廃液などの植物系原料と, 石炭, 石 油重質油などの化石燃料系原料がある. 最近は, 環境保全, 資 源およびエネルギーの有効利用の面から, 夕イヤ, 食品, 繊 維, 炭化燃料など様々な廃棄物からも活性炭が製造されてお
り,その中の一つに米の生産に伴い生成する籾殼が挙げられ る. 籾款は国内で年間約 150-180万トン排出されており，そ の成分はリグニン, セルロース, ペントサンなどの有機物質 とシリカである (Table 1). 籾款を原料とした活性炭の合成は 奥谷ら 2)により報告されており，炭化した籾殼をアルカリと 混合して高温で焼成する溶融アルカリ処理により, $3000 \mathrm{~m}^{2} / \mathrm{g}$ を超える高比表面積活性炭が生成している.このような非常 に高い比表面積は, 賦活過程でアルカリが炭素を浸食するこ とでミクロ孔が生成するためである.しかしながら, 溶融ア ルカリ処理は大量のアルカリ $(\mathrm{NaOH}, \mathrm{KOH})$ ならびに高温での 腑活を必要とするため, 高コストとなる問題がある.

本研究では, マイクロ波水熱法による籾款からの活性炭合 成を試みた，マイクロ波を液相反応に応用した場合, 急速加 熱, 選択加熱, 内部加熱が可能であり, 反応時間の大幅な短

Table 1 Composition of rice chaff (wt\%).

\begin{tabular}{ccccccc}
\hline cellulose & lignin & pentosan & crude fat & water & silica & alkali metals \\
\hline 32.7 & 21.8 & 17 & 0.4 & 8.2 & 18.8 & 1.2 \\
\hline
\end{tabular}


縮, 新規な低コストプロセス, 新物質・新機能の創製などが 期待される.これまで, $\mathrm{CdS}^{3)}, \mathrm{Ni}^{4)}, \mathrm{TiO}_{2}{ }^{5)}, \mathrm{Fe}_{2} \mathrm{O}_{3}{ }^{6)}$, ゼオライト $\mathrm{Y}^{7)}$ などの粒子合成が報告されている. 著者らは, 石炭フライ アッシュのアルカリ水熱処理によるゼオライト合成 ${ }^{8)}$, 水熱 法による $\mathrm{TiO}_{2}$ 粒子合成 ${ }^{9)}$ にイクロ波加熱を適用し, マイク 口波が水溶媒中での固体の溶解を著しく促進し, 反応効率を 高めることを明らかにした。 また, 金属アルコキシドと有機 テンプレートを含む水相を油相に分散させたW/Oエマルショ ンにマイクロ波照射することで, 水相エマルションが選択加 熱され, 球状のメソポーラスシリカ粒子の合成に成功した ${ }^{10,11)}$. このマイクロ波を籾殼炭化物のアルカリ水熱処理に活 用することにより, 高い反応活性が期待できる. また, 炭素 は高いマイクロ波吸収特性を持つため, 水溶液中でもマイク 口波を吸収し, 局所的な内部加熱により賦活が進行すると期 待できる。

\section{2 実験方法}

籾殸中のアルカリ金属等を除去するため, リーチングとし て, $300 \mathrm{ml}$ 丸底フラスコ中, 籾殼 $15 \mathrm{~g}$ を $150 \mathrm{ml}$ の $0.83 \mathrm{M} \mathrm{HCl}$ と混合し, $2 \mathrm{~h}$ 還流した. 水洗後, 電気炉中, $\mathrm{N}_{2}$ 中, $10^{\circ} \mathrm{C} / \mathrm{min}$ で昇温し, $700^{\circ} \mathrm{C}, 1 \mathrm{~h}$ 焼成して籾殼炭化物を得た. 籾殼炭化 物 $1 \mathrm{~g}$ をテフロン容器 (容量 $100 \mathrm{ml}$ ) に入れ, $40 \mathrm{ml}$ の 2.5-10M $\mathrm{NaOH}$ 水溶液を添加し, マイクロ波発生装置 MARS5X (CEM Co.) を用いて $300 \mathrm{~W}, 100-200^{\circ} \mathrm{C}$ で $15 \mathrm{~min}-5 \mathrm{~h}$ 加熱した. 比較 のため, オートクレーブ (100 mlテフロン容器 $)$ を用いて合成 を行った (通常加熱法). ろ過により生成物を回収し, $\mathrm{pH}$ 中性になるまで水洗した後, $50{ }^{\circ} \mathrm{C}$ で乾燥し, 生成物を得た. 生成物は, 蛍光 $\mathrm{X}$ 線による定量測定 (XRF-WDX; 波長分散小 型蛍光 $X$ 線分析装置 Supermini (俳りガク製)), $\mathrm{N}_{2}$ 吸着測定 (BELSORP-miniII (日本ベル侏製 ))により評価した。

\section{3 実験結果および考察}

3.1 籾殼の炭化温度

籾殼の炭化温度を $600-1000^{\circ} \mathrm{C}$ で変え, 最適の炭化温度を調 查した。炭化条件と炭化収率, 比表面積, 組成分析結果を Table 2 に示す. Fig. 1 は炭化物の $\mathrm{N}_{2}$ 吸着等温線であり, Fig.2 に炭化温度による炭化物収率と比表面積の変化を示している。 炭化試料は主に炭素と残留 $\mathrm{SiO}_{2}$ からなり, アルカリ残椬とし てカリウムが存在していることが分かる. 炭化温度の上昇と
ともに炭化収率が減少しており，これは籾殻からの有機物の 揮散のためである. $\mathrm{N}_{2}$ 吸着等温線は, 炭化温度が低い場合, 低圧部での立ち上がりが大きくミクロ孔が多いことが分かる. 炭化温度が高くなるとミクロ孔が減少し, 高圧部での立ち上 がりが大きくなりサイズの大きなマクロ孔が生成しているこ

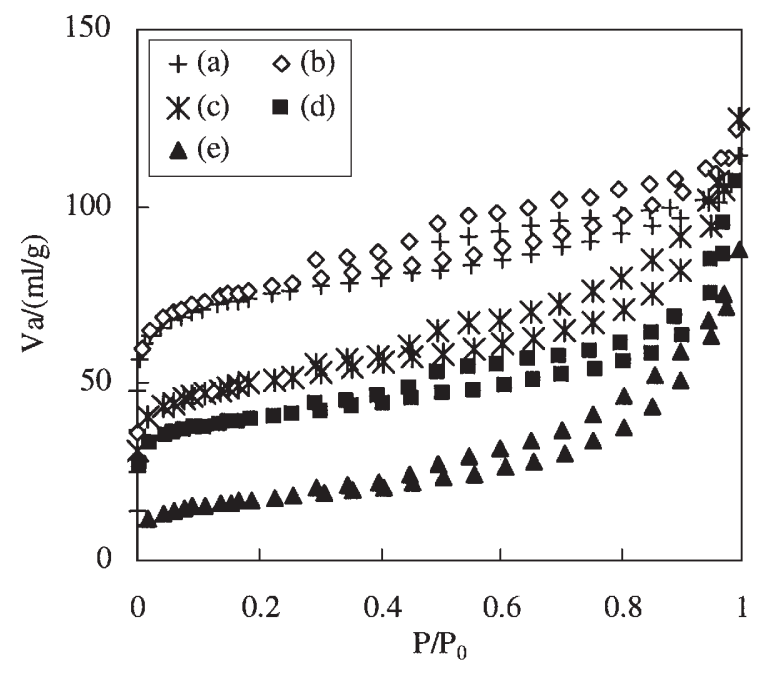

Fig.1 $\mathrm{N}_{2}$ adsorption isotherm of charcoal obtained by carbonization of rice chaff at (a) $600^{\circ} \mathrm{C}$, (b) $700^{\circ} \mathrm{C}$, (c) $800^{\circ} \mathrm{C}$, (d) $900^{\circ} \mathrm{C}$ and (e) $1000^{\circ} \mathrm{C}$.

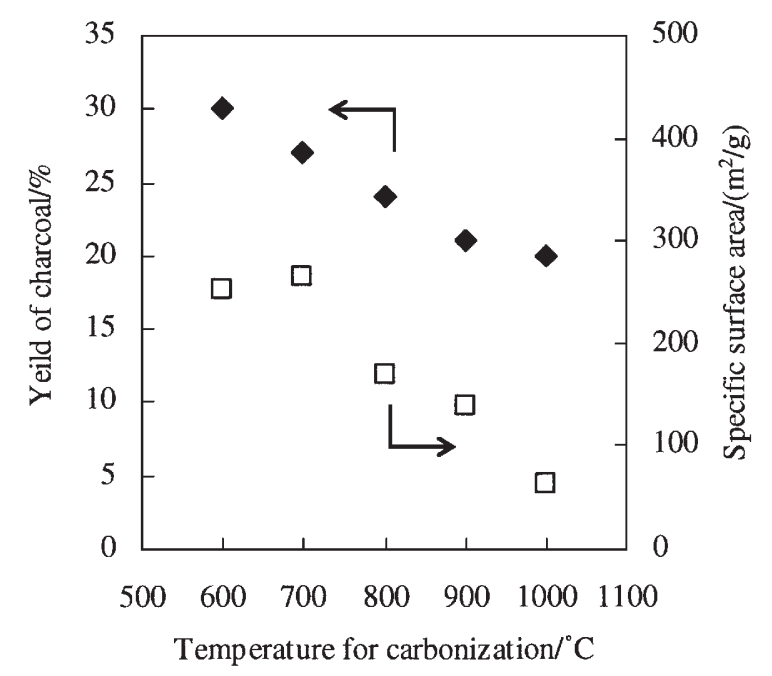

Fig.2 Changes in yield of charcoal and specific surface area with temperature for carbonization.

Table 2 Condisions for the carbonization of rice chaff.

\begin{tabular}{cccccc}
\hline \multirow{2}{*}{$\begin{array}{c}\text { Temperature for } \\
\text { carbonization }\left({ }^{\circ} \mathrm{C}\right)\end{array}$} & $\begin{array}{c}\text { Yield of } \\
\text { charcoal }(\%)\end{array}$ & $\begin{array}{c}\text { Specific surface } \\
\text { area }\left(\mathrm{m}^{2} / \mathrm{g}\right)\end{array}$ & \multicolumn{3}{c}{ Composition (wt\%) } \\
\cline { 5 - 6 } 600 & 30 & 253 & 61 & 34 & $\mathrm{C}$ \\
700 & 27 & 265 & 57 & 38 & 4.7 \\
800 & 24 & 170 & 53 & 42 & 5.2 \\
900 & 21 & 140 & 49 & 45 & 6.3 \\
1000 & 20 & 62 & 47 & 47 & 5.7 \\
\hline
\end{tabular}


とが分かる. 結果として炭化温度上昇に伴い比表面積が減少 した.これは, 焼成温度の上昇によるミクロ孔の崩壊および 残留 $\mathrm{SiO}_{2}$ の焼結によるものと考えられる. 以上の結果から, 炭化温度は $700^{\circ} \mathrm{C}$ にどめた。

\section{2 アルカリ水熱処理による活性炭合成}

アルカリ水熱処理に対する通常加熱とマイクロ波加熱の比 較, および, $\mathrm{NaOH}$ 濃度, 加熱温度と時間の影響を調査した。 合成条件と結果を Table 3 に示す。

\section{2 .1 加熱法の影響}

籾殼炭化物を $5 \mathrm{M} \mathrm{NaOH}$ 水溶液中, 通常加熱では $24 \mathrm{~h}$, マ イクロ波加熱では $30 \mathrm{~min}$, 加熱した. Fig. 3 に生成物の $\mathrm{N}_{2}$ 吸 着等温線を示す. 籾殼炭化物 (Fig.3 (a)) は比表面積 $370 \mathrm{~m}^{2} / \mathrm{g}$ 程 度であり, 約 $35 \mathrm{wt} \%$ の $\mathrm{SiO}_{2}$ を含んでいた.アルカリ水熱処 理を行ったところ,いずれの加熱法でも $\mathrm{SiO}_{2}$ 含有量は $0.5 \mathrm{wt} \%$ 以下となり, 比表面積は通常加熱 (Fig.3 (c)) で $690 \mathrm{~m}^{2} / \mathrm{g}$, マイ クロ波加熱 (Fig.3 (d)) で $1060 \mathrm{~m}^{2} / \mathrm{g}$ に向上した. 籾殼炭化物を アルカリ水溶液中, 室温で $24 \mathrm{~h}$ 擋汼したところ(Fig.3 (b)), $\mathrm{SiO}_{2}$ 含有量は $7.5 \mathrm{wt} \%$, 比表面積は $770 \mathrm{~m}^{2} / \mathrm{g}$ を示したことから, ア ルカリ処理により籾款炭化物中の $\mathrm{SiO}_{2}$ が除去されると, 加熱 なしでも比表面積は向上することがわかり, 通常加熱での比 表面積の増加は, アルカリ処理に伴う $\mathrm{SiO}_{2}$ の除去によるもの であると示唆された. 一方, マイクロ波加熱では生成物の比 表面積が $1000 \mathrm{~m}^{2} / \mathrm{g}$ を超えたことから, 加熱過程で籾殼炭化物 が賦活されたと考えられる. Fig.3より, マイクロ波加熱では 室温あるいは通常加熱に比べて低相対圧領域での吸着等温線 の立ち上がりが大きく, ミクロ孔が発達したことが示唆され る. 一般的なアルカリ賦活では, 賦活過程でアルカリが炭素 を浸食することでミクロ孔が生成することから, マイクロ波 アルカリ水熱処理においても炭素へのアルカリの浸食が促進 され，ミクロ孔が発達したと考えられる.

\subsection{2 $\mathrm{NaOH}$ 濃度の影響}

籾款炭化物を 2.5-10 M NaOH 水溶液中, $100^{\circ} \mathrm{C}$ で $1 \mathrm{~h}$ マイ クロ波加熱し, アルカリ水熱処理時の $\mathrm{NaOH}$ 濃度の影響につ
いて調査した.いずれの濃度で処理しても, $\mathrm{SiO}_{2}$ 含有量は $1 \mathrm{wt} \%$ 以下に低下した. Fig. 4 に生成物の $\mathrm{N}_{2}$ 吸着等温線を示す. 比 表面積は $\mathrm{NaOH}$ 濃度 $2.5 \mathrm{M}$ で $620 \mathrm{~m}^{2} / \mathrm{g}, 5 \mathrm{M}$ で $900 \mathrm{~m}^{2} / \mathrm{g}, 10 \mathrm{M}$ で $860 \mathrm{~m}^{2} / \mathrm{g}$ であった. $2.5 \mathrm{M} \mathrm{NaOH}$ で処理した場合, 低相対圧 領域における $\mathrm{N}_{2}$ 吸着等温線の上昇が小さかったことから, $\mathrm{SiO}_{2}$ 成分がほとんど除去されたにも関わらず比表面積が小さ かったのは, 賦活に必要なアルカリが不足したためミクロ孔 が発達しなかったためだと示唆された. 以上から, マイクロ 波アルカリ水熱処理時の $\mathrm{NaOH}$ 濃度は $5 \mathrm{M}$ が最適であること がわかった。

3.2 .3 加熱温度と時間の影響

籾款炭化物を $5 \mathrm{M} \mathrm{NaOH}$ 水溶液中, $100-200^{\circ} \mathrm{C}$ で $15 \mathrm{~min}-5 \mathrm{~h}$ マイクロ波加熱し, 加熱温度と時間の影響を調查した. 加熱 時間を $1 \mathrm{~h}$ とし, 温度を $100^{\circ} \mathrm{C}, 150^{\circ} \mathrm{C}, 200^{\circ} \mathrm{C}$ と変化させたと ころ, $\mathrm{N}_{2}$ 吸着等温線と比表面積に大きな変化はなかった. 加

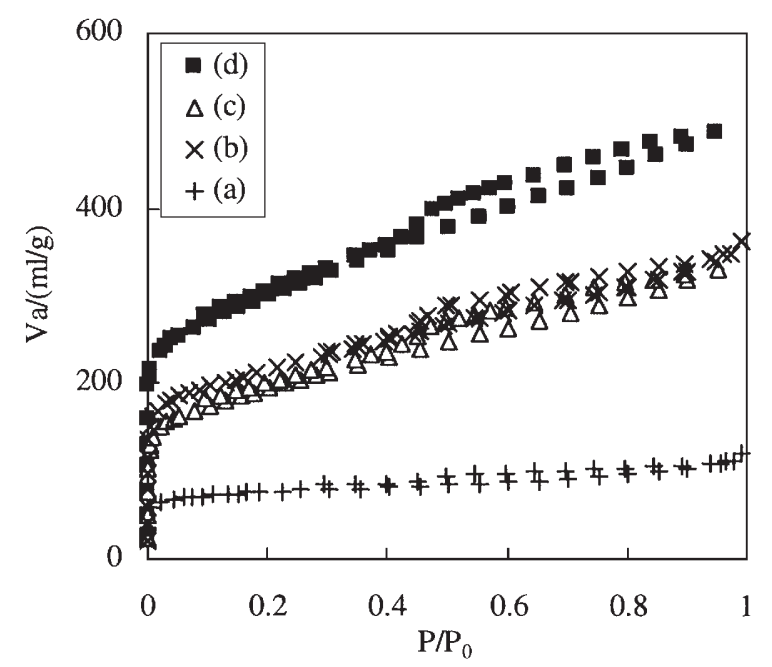

Fig. $3 \quad \mathrm{~N}_{2}$ adsorption isotherm of charcoal (a) before and (b-d) after activation with $5 \mathrm{M} \mathrm{NaOH}$ aqueous solution. The condition for activation was set as follows: (b) for $24 \mathrm{~h}$ at room temperature, (c) for $24 \mathrm{~h}$ at $100^{\circ} \mathrm{C}$ by using autoclave and (d) for $30 \mathrm{~min}$ at $100^{\circ} \mathrm{C}$ under microwave irradiation.

Table 3 Synthetic conditions of activated carbon by microwave hydrothermal method.

\begin{tabular}{cccccccc}
\hline \multirow{2}{*}{$\begin{array}{c}\text { Temperature for } \\
\text { carbonization }\left({ }^{\circ} \mathrm{C}\right)\end{array}$} & $\mathrm{NaOH}(\mathrm{M})$ & Heating method Temperature $\left({ }^{\circ} \mathrm{C}\right)$ & Time $(\mathrm{h})$ & $\begin{array}{c}\text { Specific surface } \\
\text { area }\left(\mathrm{m}^{2} / \mathrm{g}\right)\end{array}$ & \multicolumn{2}{c}{ Composition (wt\%) } \\
\cline { 6 - 9 } & & & & & $\mathrm{C}$ & $\mathrm{Si}$ \\
\hline 700 & 5 & $\mathrm{MW}$ & 100 & 0.5 & 1060 & 99 & 1 \\
700 & 5 & $\mathrm{CH}$ & 100 & 24 & 686 & 99 & 1 \\
700 & 5 & Non & R.T. & 24 & 765 & 99 & 1 \\
\hline 700 & 2.5 & MW & 100 & 1 & 615 & 99 & 1 \\
700 & 5 & MW & 100 & 1 & 899 & 99 & 1 \\
700 & 10 & MW & 100 & 1 & 860 & 99 & 1 \\
\hline 700 & 5 & MW & 150 & 1 & 856 & 99 & 1 \\
700 & 5 & MW & 200 & 1 & 824 & 100 & 0 \\
\hline 700 & 5 & MW & 100 & 0.25 & 838 & 99 & 1 \\
700 & 5 & MW & 100 & 5 & 848 & 99 & 1 \\
\hline
\end{tabular}




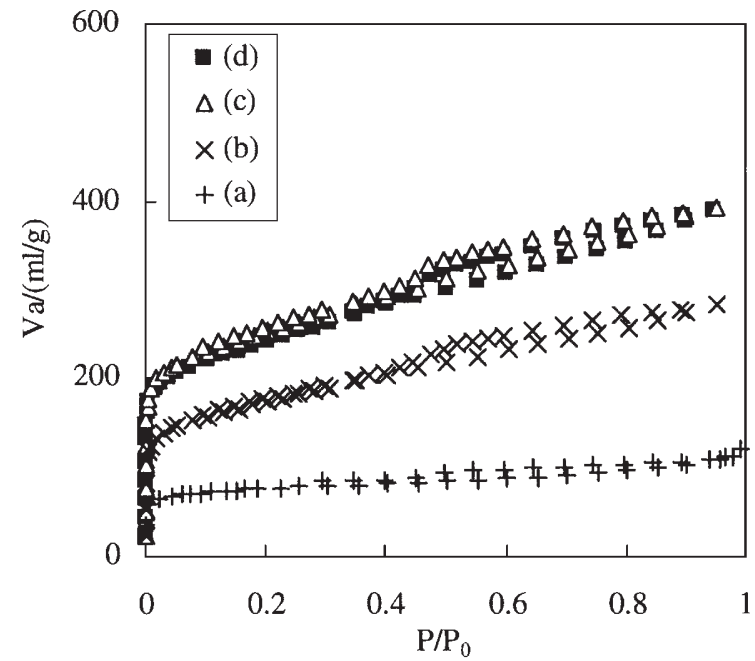

Fig.4 $\mathrm{N}_{2}$ adsorption isotherm of charcoal (a) before and (b-d) after activation with $\mathrm{NaOH}$ aqueous solution for $1 \mathrm{~h}$ under microwave irradiation. The $\mathrm{NaOH}$ concentration was set at (b) $2.5 \mathrm{M}$, (c) $5 \mathrm{M}$ and (d) $10 \mathrm{M}$.

熱温度を $100^{\circ} \mathrm{C}$ とし, 反応時間の影響を調査したところ, XRFWDX 分析より, 炭化物中の $\mathrm{SiO}_{2}$ は $15 \mathrm{~min}$ の処理でほとんぞ 除去されたことがわかった. Fig. 5 に加熱温度 $100^{\circ} \mathrm{C}$ で時間を 変えたときの生成物の $\mathrm{N}_{2}$ 吸着等温線を示す. 比表面積は 15 $\min$ で $840 \mathrm{~m}^{2} / \mathrm{g}, 30 \mathrm{~min}$ で $1060 \mathrm{~m}^{2} / \mathrm{g}, 1 \mathrm{~h}$ で $900 \mathrm{~m}^{2} / \mathrm{g}, 5 \mathrm{~h}$ で 850 $\mathrm{m}^{2} / \mathrm{g}$ であった. 吸着等温線の低相対圧領域に着目すると, 加 熱時間の増加に伴いミクロ孔の増加が見られ，さらに長時間 加熱を行うとミクロ孔が滅少したことが示唆された. マイク 口波水熱法において炭素にアルカリが浸食するためには 30 $\min$ 程度の処理が必要であり, それ以上では, ミクロ孔の崩 壊により比表面積が減少することがわかった。

$$
4 \text { ま と め }
$$

籾殻をマイクロ波アルカリ水熱処理により活性炭に転換し た. 籵殸を $\mathrm{N}_{2}$ 中で焼成して得られる炭化物は $\mathrm{SiO}_{2}$ 成分を多 量に含んでいたが, アルカリ水熱処理を行うと $\mathrm{SiO}_{2}$ 含有量は 隇少し, 比表面積が向上した. 通常加熱法では $\mathrm{SiO}_{2}$ 除去に伴 う比表面積の向上のみが見られたのに対し，マイクロ波加熱 法では比表面積増加が顕著であった. 水熱プロセスにおいて マイクロ波照射により炭化物へのアルカリの浸食が促進され たことが示唆され, マイクロ波が炭化物の賦活に有効である ことが証明された。

\section{文献}

1) I. Abe, et al.: Sumi no Seizou to Riyou Gijutu, NTS Inc., (2009).

2) Miho Tanaka and Takeshi Okutani: "Production of Activated carbon from Rice Hulls", Preprints of Annual Meeting of The Ceramic Society of Japan, (2009)213.

3) Y. Wada, H. Kuramoto, J. Anand, T. Kitamura, T. Sakata, H.

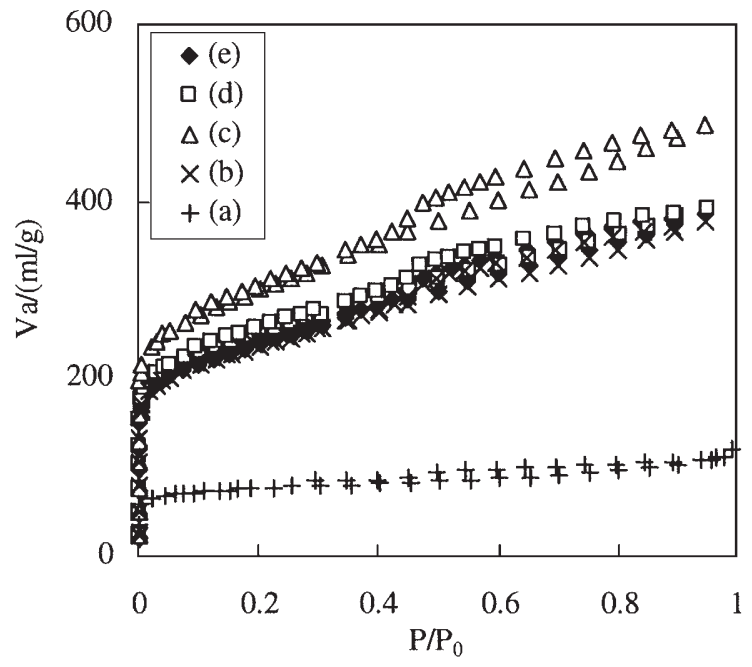

Fig.5 $\mathrm{N}_{2}$ adsorption isotherm of charcoal (a) before and (b-d) after activation with $5 \mathrm{M} \mathrm{NaOH}$ aqueous solution under microwave irradiation. The heating time was set for (b) 15 min, (c) $30 \mathrm{~min}$, (d) $1 \mathrm{~h}$ and (e) $5 \mathrm{~h}$.

Mori, and S. Yanagida: "Microwave-assisted size control of CdS nanocrystallites", J. Mater. Chem., 11(2001)1936-1940.

4) Y. Wada, H. Kuramoto, T. Sakata, H. Mori, T. Sumida, T. Kitamura, and S. Yanagida: "Preparation of Nano-sized Nickel Metal Particles by Microwave Irradiation", Chem. Lett., 28 (1999)607-608.

5) T. Yamamoto, Y. Wada, H. Yin, T. Sakata, H. Mori, and S. Yanagida: "Microwave-Driven Polyol Method for Preparation of $\mathrm{TiO}_{2}$ Nanocrystallites", Chem. Lett., 31 (2002)964-965.

6) H. Katsuki and S. Komarneni: "Microwave-Hydrothermal Synthesis of Monodispersed Nanophase $\alpha-\mathrm{Fe}_{2} \mathrm{O}_{3}{ }^{\prime \prime}, \mathrm{J}$. Am. Ceram. Soc., 84(2001)2313-2317.

7) A. Arafat, J.C. Jansen, A.R. Ebaid, and H. van Bekkumt: "Microwave preparation of zeolite Y and ZSM-5", Zeolites, 13(1993)162-165.

8) M. Inada, H. Tsujimoto, Y. Eguchi, N. Enomoto, and J. Hojo: "Microwave-assisted Zeolite Synthesis from Coal Fly Ash in Hydrothermal Process", Fuel, 84(2005)1482-1486.

9) M. Inada, K. Kamada, N. Enomoto, and J. Hojo: "Microwave Effect for Synthesis of $\mathrm{TiO}_{2}$ Particles by Self-hydrolysis of $\mathrm{TiOCl}_{2}{ }^{\prime}$, Journal of the Ceramic Society of Japan, 114(2006) 814-818.

10) M. Inada, A. Nishinosono, K. Kamada, N. Enomoto, and J. Hojo: "Microwave-assisted Sol-gel Process for Production of Spherical Mesoporous Silica Materials", Journal of Materials Science, 43(2008) 2362-2366.

11) M. Inada, N. Enomoto, and J. Hojo: "Synthesis and Photocatalytic Activity of Mesoporous $\mathrm{SiO}_{2}-\mathrm{TiO}_{2}{ }^{\prime \prime}$, Research on Chemical Intermediates, 36(2010) 115-120. 